\title{
Origin and status of the Great Lakes wolf
}

\author{
STEPHAN KOBLMÜLLER, *§** MARIA NORD, *§ROBERT K. WAYNE† and JENNIFER A. LEONARD *¥ף \\ *Department of Evolutionary Biology, Evolutionary Biology Centre, Uppsala University, Norbyvägen 18d, SE-75236 Uppsala, Sweden, \\ $\dagger$ †epartment of Ecology and Evolutionary Biology, University of California, Los Angeles, CA 90095, USA, $\ddagger$ Center for Conservation \\ and Evolutionary Genetics, National Zoological Park and National Museum of Natural History, Smithsonian Institution, Washington, \\ DC 20013, USA, ๆEstación Biológica de Doñana-CSIC, Avd. Americo Vespuccio s/n, 41092 Seville, Spain
}

\begin{abstract}
An extensive debate concerning the origin and taxonomic status of wolf-like canids in the North American Great Lakes region and the consequences for conservation politics regarding these enigmatic predators is ongoing. Using maternally, paternally and biparentally inherited molecular markers, we demonstrate that the Great Lakes wolves are a unique population or ecotype of gray wolves. Furthermore, we show that the Great Lakes wolves experienced high degrees of ancient and recent introgression of coyote and western gray wolf mtDNA and Y-chromosome haplotypes, and that the recent demographic bottleneck caused by persecution and habitat depletion in the early 1900s is not reflected in the genetic data.
\end{abstract}

Kewords: aDNA, Canis latrans, Canis lupus lycaon, conservation, hybridization, introgression, Y chromosome

\section{Introduction}

Hybridization and introgression have long been recognized by botanists as important factors influencing evolution (e.g. Abbott 1992; Arnold 1997; Ellstrand \& Schierenbeck 2000), whereas its importance in animal evolution has been a subject of extensive debate (Arnold 1992; Dowling \& Secor 1997; Seehausen 2004). Recently, numerous studies have demonstrated that closely related animal species often share a history of introgressive hybridization (e.g. Melo-Ferreira et al. 2005; Roca et al. 2005; Berthier et al. 2006; Patterson et al. 2006), indicating that hybridization may be frequent in some cases before the completion of reproductive isolation in animals. Even though it seems that natural hybridization and introgression are more common in animals than previously assumed, it is still not known how widespread this phenomenon is and whether particular taxa or biogeographical regions are more prone to it. A recent spatially explicit simulation study (Currat et al. 2008) demonstrated that massive introgression of neutral genes can occur during the invasion of an occupied area as

Correspondence: Jennifer Leonard, Fax: +46-18-471 6310; E-mail: jennifer.leonard@ebc.uu.se

$\S$ Stephan Koblmüller and Maria Nord contributed equally to this work.

**Current address: Department of Zoology, Karl-FranzensUniversity Graz, Universitätsplatz 2, 8010 Graz, Austria long as interbreeding is not severely prevented between the invading and the local species. Importantly, it was found that introgression occurs almost exclusively from the local to the invading species, regardless of the relative densities of the two species. Introgressive hybridization can have a variety of consequences, but its greatest evolutionary importance might lie in it being the source of new genetic variability within taxa. However, under different circumstances it might cause a merging of the hybridizing species (Arnold 1997). For the latter reason, conservation policy generally discourages hybridization between species because hybridization can jeopardize the continued integrity of the hybridizing species (O’Brien \& Mayr 1991; Leonard \& Wayne 2008).

The wolves of the Great Lakes region in the USA were almost exterminated at the beginning of the last century due to habitat depletion associated with the spread of agriculture and direct persecution. However, they have recovered under the protection of the US Endangered Species Act to currently $>3000$ individuals, resulting in an extensive debate concerning their potential delisting. Over the last century, coyotes have invaded this region and hybridized with wolves (Lehman et al. 1991, Leonard \& Wayne 2008). At present, there is still no general consensus about which species of wolf-like canid currently inhabits the Great Lakes region and if the integrity of the population is under threat by hybridization. The Great Lakes (GL) wolf is morphologically distinct from both western gray 


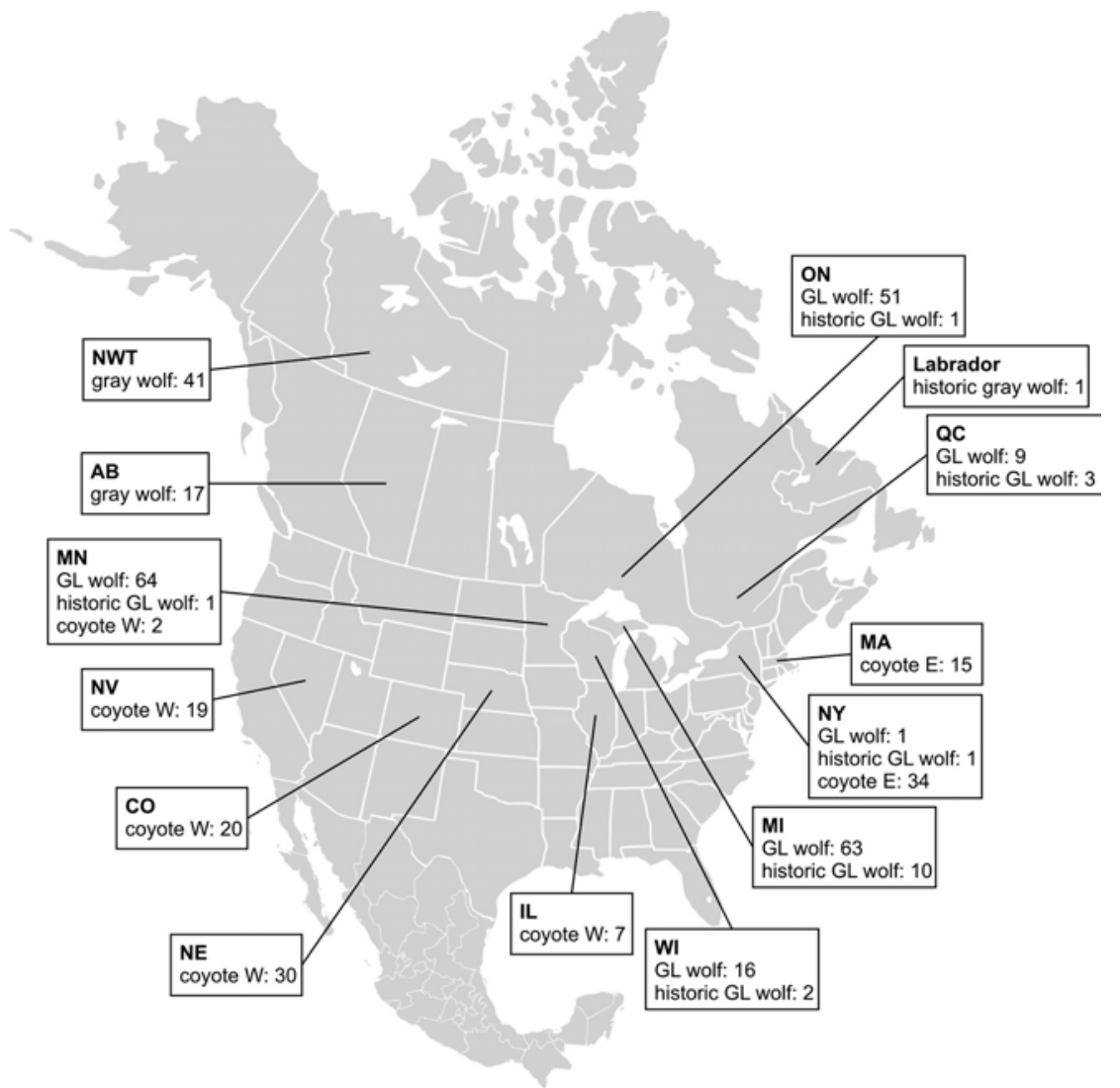

Fig. 1 Map of North America, showing the number of samples per taxon and state. NWT, Northwest Territories; AB, Alberta; MN, Minnesota; WI, Wisconsin; MI, Michigan; ON, Ontario; QC, Quebec; NY, New York; MA, Massachusetts; NE, Nebraska; CO, Colorado; NV, Nevada; IL, Illinois.

wolves (Canis lupus) and coyotes (Canis latrans) (Nowak 2002). It has been suggested that the GL wolf is either (i) a smaller subspecies of the gray wolf (Canis lupus lycaon), possibly resulting from hybridization between gray wolves (C. lupus) and red wolves (Canis rufus) (Nowak 2002); (ii) a hybrid zone between gray wolves (C. lupus) and coyotes (C. latrans) (e.g. Lehman et al. 1991; Roy et al. 1994); or (iii) a distinct species (C. Iycaon) closely related to, and perhaps conspecific with, the red wolf (C. rufus). This unique wolflike canid is hypothesized to have evolved from a coyotelike ancestor, thus representing a small wolf indigenous to North America (Wilson et al. 2000; Kyle et al. 2006).

Here we use maternally, paternally and biparentally inherited molecular markers to analyse modern and historic pre-bottleneck and pre-coyote invasion GL wolves, western gray wolves and coyotes in order to evaluate (i) alternative hypotheses regarding the evolutionary origin of the GL wolves; (ii) ongoing hybridization between GL wolves, western gray wolves and coyotes in the Great Lakes region; and (iii) population integrity.

\section{Material and methods}

\section{Samples and extraction}

The modern samples used in this study included western gray wolves from the Northwest Territories and Alberta,
Canada; GL wolves from Ontario and Quebec, Canada and Minnesota, Wisconsin, Michigan, and New York, USA; coyotes from New York, Massachusetts, Nebraska, Colorado, Nevada and Illinois, USA. Western coyotes from Nebraska, Colorado, Nevada and Illinois correspond to the original distribution of North American coyotes, whereas eastern coyotes from New York and Massachusetts represent the recent northeastward range expansion. The GL wolf samples from Canada and Minnesota were from Lehman etal. (1991) and Roy et al. (1994).

Historic samples consisting of skulls from the collection of the National Museum of Natural History, Smithsonian Institution, included $18 \mathrm{GL}$ wolf samples from Ontario and Quebec, Canada and Michigan, Wisconsin, Minnesota and New York and a historic gray wolf from Labrador (Fig. 1, Table 1). The historic GL wolves were all collected before coyotes became established in the region.

Whole genomic DNA was extracted from recent muscle tissue samples using a modified phenol/chloroform protocol (Sambrook et al. 1989). Extraction of historic specimens followed Leonard et al. (2005).

\section{Amplification and sequencing of the mitochondrial control region}

Amplification of $420-425$ bp of the $5^{\prime}$ end of the mitochondrial control region followed Vilà et al. (1999) for the 


\begin{tabular}{|c|c|c|c|}
\hline Museum no. & Subspecies & Year & Locality \\
\hline USNM 178452 & Canis lupus lycaon & $1910 *$ & Algonquin Park, Ontario, Canada \\
\hline USNM 140561 & C.I. lycaon & 1905 & Mattawa, Quebec, Canada \\
\hline USNM 140562 & C. I. Iycaon & 1905 & Mattawa, Quebec, Canada \\
\hline USNM 223171 & C. I. Iycaon & 1916 & Quebec City, Quebec, Canada \\
\hline USNM 148897 & C. I. lycaon & 1906 & Marquette Co., Michigan, USA \\
\hline USNM 148898 & C. I. lycaon & 1906 & Marquette Co., Michigan, USA \\
\hline USNM 168820 & C. I. Iycaon & 1909 & Calderwood, Michigan, USA \\
\hline USNM 168821 & C. I. Iycaon & 1909 & Calderwood, Michigan, USA \\
\hline USNM 170566 & C. I. lycaon & 1910 & Hulbert, Michigan, USA \\
\hline USNM 170567 & C. I. Iycaon & 1910 & Taquahmenon River, Michigan, USA \\
\hline USNM 170621 & C. I. Iycaon & 1910 & Taquahmenon River, Michigan, USA \\
\hline USNM 170692 & C. I. lycaon & 1910 & Cusino, Michigan, USA \\
\hline USNM 171132 & C. I. lycaon & 1911 & Sault Sainte Marie, Michigan, USA \\
\hline USNM 180798 & C. I. Iycaon & 1912 & Dickinson Co., Michigan, USA \\
\hline USNM A01804 & C. I. lycaon & $\dagger$ & Adirondacks, New York, USA \\
\hline USNM 150421 & C. I. Iycaon & 1907 & Eagle River, Wisconsin, USA \\
\hline USNM 156838 & C. I. lycaon & 1908 & Taylor Co., Wisconsin, USA \\
\hline USNM 45560 & C. I. lycaon & 1892 & Elk River, Minnesota, USA \\
\hline USNM 210059 & Canis lupus labradorius & 1912 & Porcupine, Labrador, Canada \\
\hline
\end{tabular}

Table 1 Historic wolf samples from the National Museum of Natural History, Smithsonian Institution. Collection number, subspecies as in collection, date, and locality are indicated

*Approximation, †specimen accessioned before 1892.

recent specimens and Leonard et al. (2005) for the historic samples. Polymerase chain reaction (PCR) products were purified using ExoSAP-IT (Amersham Biosciences) and sent to Macrogen (Macrogen Online Sequencing System) for sequencing with same primers as PCR. When available, previously published sequences were used (Leonard et al. 2005, Musiani et al. 2007, Hailer \& Leonard 2008, Leonard \& Wayne 2008, Muñoz-Fuentes et al. 2009). Sample size for mtDNA was as follows: 58 gray wolves, $202 \mathrm{GL}$ wolves, 48 eastern coyotes, 78 western coyotes, 15 historic GL wolves, 1 historic gray wolf.

\section{Nuclear and Y-chromosomal microsatellite genotyping}

Twenty-six unlinked biparentally inherited autosomal microsatellites were typed for 58 gray wolves, 195 GL wolves, 48 eastern coyotes, 78 western coyotes and 13 historic GL wolves: Ren94K11, C17.402, Ren239K24, C18.460, Ren274F18, Ren181K04, C11.873, Ren73F08, C02.894, Ren204K13, Ren160J02, Ren106I06 (Breen et al. 2001), FH3109, FH2887, FH2914, FH2785, FH2759 (Guyon et al. 2003), Ren37H09, Ren49F22 (Jouquand et al. 2000), c2017 (Francisco et al. 1996), u109, u225, u250, u253 (Ostrander et al. 1993), vWF (Shibuya et al. 1994) and PEZ05 (PerkinElmer, Zoogen; see NHGRI Dog Genome Project at http://research. nhgri.nih. gov/dog_genome/). Amplification of the microsatellite loci followed Björnerfeldt et al. (2008). PCR products were pooled in seven different batches for genotyping.

Allelic dropout, where one allele at a heterozygous locus fails to amplify, is the most common error associated with amplifications from low concentration DNA, such as historic
DNA, resulting in a potential misinterpretation of a heterozygous individual as being homozygous at that particular locus (Taberlet et al. 1996). Therefore, we only scored historic genotypes as homozygous when the same single allele was amplified in at least four replicate PCRs. When only one allele was amplified from a sample fewer than four replicates - due to PCR failure and depletion of DNA extract - we scored the genotype as consisting of the observed allele and one missing allele. Allele frequencies for differentiation analysis $\left(\theta_{\mathrm{ST}}\right.$; see below) were then calculated relative to the total number of scored alleles. This is justified by observations that, despite higher rates of allele dropout in loci with large fragments, dropout was random with respect to allele sizes within a locus (Sefc et al. 2003).

A total of six Y-chromosomal microsatellites were typed for all males and samples of unknown sex (final sample size: 30 gray wolves, 111 GL wolves, 25 eastern coyotes, 41 western coyotes, 4 historic GL wolves): 650-79.3, 990-35 (Bannasch et al. 2005), MS41A, MS41B, MS34A, MS34B (Sundqvist et al. 2001). All amplifications were carried out in 10- $\mu \mathrm{L}$ reactions. The PCR mix for $650-79.3$ and $990-35$ included 1× Smart Taq buffer (QIAGEN), $2.5 \mathrm{~mm} \mathrm{MgCl}_{2}$, $0.25 \mu \mathrm{m}$ of each dNTP, $0.4 \mu \mathrm{m}$ of each primer, $0.25 \mathrm{U}$ Smart Taq (QIAGEN) and $1 \mu \mathrm{L}$ of DNA template ( 10 ng). The PCR profile for 650-79.3 included an initial denaturation step at $95^{\circ} \mathrm{C}$ for $15 \mathrm{~min}$ followed by 38 cycles (30 s annealing temperature at $65^{\circ} \mathrm{C}$, extension at $72{ }^{\circ} \mathrm{C}$ for $1 \mathrm{~min}$, followed by denaturation at $95^{\circ} \mathrm{C}$ for $30 \mathrm{~s}$ ) and a final annealing step at $65{ }^{\circ} \mathrm{C}$ for $1 \mathrm{~min}$ and an extension step at $72^{\circ} \mathrm{C}$ for $10 \mathrm{~min}$. For 990-35 the annealing temperature was $57^{\circ} \mathrm{C}$. Amplification of MS41A, MS41B, MS34A and MS34B followed 
Hailer \& Leonard (2008). For genotyping, the PCR products 650-79.3 and 990-35 were pooled. Genotyping was carried out on a MegaBACE 1000 instrument (Amersham Biosciences). Genotypes were identified using the software Genetic Profiler version 2.2 (Amersham Biosciences).

\section{Data analysis}

Genetic diversity indices for mtDNA sequences and Ychromosomal data [number of haplotypes $(H)$, haplotype diversity $\left(H_{\mathrm{D}}\right)$, and, for mtDNA sequences, nucleotide diversity $(\pi)$ ] were calculated in Arlequin version 3.0 (Excoffier et al. 2005). Microsatellite variability in modern samples was estimated as the number of alleles $\left(N_{\mathrm{A}}\right)$, allelic richness $\left(A_{\mathrm{R}}\right)$, observed $\left(H_{\mathrm{O}}\right)$ and expected $\left(H_{\mathrm{E}}\right)$ heterozygosity, using Arlequin. We used Micro-Checker 2.2 (van Oosterhout et al. 2004) to test for errors due to stuttering, large allelic dropout and the presence of null alleles. Exact tests of Hardy-Weinberg equilibrium for each microsatellite locus were calculated in Arlequin with Markov chains of 100000 steps following 1000 dememorization steps. We also estimated the probability of linkage disequilibrium between loci in Arlequin based on 10000 permutations. $P$ values were corrected for multiple testing following the method of Benjamini \& Hochberg (1995).

Mitochondrial sequences were checked and aligned manually to minimize the number of indels using the program Sequencher version 4.6 (Gene Codes). The best-fit model of nucleotide substitution suggested by ModelGenerator version 0.85 (Keane et al. 2006) was $\mathrm{HKY}+\mathrm{I}+\mathrm{G}$ (Hasegawa et al. 1985) with base frequencies $A=0.27609$, $\mathrm{C}=0.29369, \mathrm{G}=0.15267$ and $\mathrm{T}=0.27755$, proportion of invariable sites $\mathrm{I}=0.50$, and a gamma shape parameter $\alpha=0.43$. Pairwise $\mathrm{HKY}+\mathrm{I}+\mathrm{G}$ distances between individual sequences computed in paup (Swofford 2002) were imported into mega 4 (Tamura et al. 2007) to visualize phylogenetic relationships by means of a neighbour-joining (NJ) tree.

Due to complete linkage of all loci on the Y-chromosome, composite Y-chromosome genotypes represent haplotypes. Phylogenetic relationships among the Y-chromosomal haplotypes were visualized by a full median-joining network (Bandelt et al. 1995, Bandelt et al. 1999) with maximum parsimony post-processing (Polzin \& Daneschmand 2003) as implemented in Network (version 4.5; available at www.fluxus-engineering.com/sharenet.htm), putting equal weight on each locus.

We analysed the genetic structure based on autosomal microsatellites (excluding the historic samples) with the Bayesian model-based clustering method implemented in Structure 2.2 (Falush et al. 2007). The log likelihood of our data $[\ln \operatorname{Pr}(X \mid K)]$ was estimated, given different numbers of genetic clusters $K$, using an admixture model with independent allele frequencies and ignoring prior population information. To assess the possible range of $K$, short [20 000 burn-in cycles, 100000 Markov chain Monte Carlo (MCMC) iterations] runs for $K=1-17$ were repeated five times. Based on the results of these initial runs, 10 long runs (20000 burn-in cycles, 1000000 MCMC iterations) were run for $K=1-7$. Following Evanno et al. (2005) we calculated $\Delta K$, which corresponds to the rate of change of the likelihood between successive $K$ values. The modal value of this distribution was considered as the uppermost level of genetic structuring (Evanno et al. 2005). To visualize the distribution of genetic variation in the autosomal microsatellites across individuals, we performed a factorial correspondence analysis (FCA) in Genetix 4.05 (Belkhir et al. 1996-2004). Population bottlenecks are expected to cause hetorozygosity excess compared to expectations based on the observed number of alleles at microsatellite loci (Cornuet \& Luikart 1996). We used Wilcoxon tests to evaluate whether the number of loci with excess heterozygosity was significantly larger than expected assuming a two-phase mutation model with 90\% single-step mutation (SSM) and 10\% infinite allele model (IAM, Luikart et al. 1998) implemented in the program Bottleneck (Piry et al. 1999).

To assess whether the genetic composition of the historic GL wolves differed significantly from that of the modern samples, we calculated locus-by-locus $\theta_{\mathrm{ST}}$ (Weir \& Cockerham 1984) from allele frequencies at 20 microsatellite loci (the loci with the largest fragment sizes did not amplify in any of the historic samples) and evaluated the significance with 10000 permutations as implemented in Arlequin 3. Global $\theta_{\text {ST }}$ was calculated as the ratio of the average locus specific $V_{a}$ (variances among groups) and the averages of total variances. Locus-by-locus probabilities were combined to a global $P$ value by means of Stouffer 's Z-transform test (Stouffer et al. 1949; also see Whitlock 2005). We used this approach because the standard amova in Arlequin is very sensitive to missing data, which is the case in our historic sample. For comparative purpose, we also estimated microsatellite $\theta_{\mathrm{ST}}$ between the historic GL samples and the modern gray wolves, eastern and western coyotes, respectively using the locus-by-locus approach as described above and between modern GL samples and modern gray wolves, eastern and western coyotes using standard amova in Arlequin 3. Furthermore, we estimated $\theta_{\mathrm{ST}}$ between historic and modern GL wolves from mtDNA haplotypes.

\section{Results}

\section{Mitochondrial DNA sequence data}

The NJ tree (Fig. 2a) shows two clades with bootstrap support of $100 \%$, of which one contains all western gray wolf haplotypes (the 'wolf clade') and the other all coyote haplotypes (the 'coyote clade'). In contrast, GL wolves from all locations around the Great Lakes were found in both clades, with 75 and 142 individuals possessing 


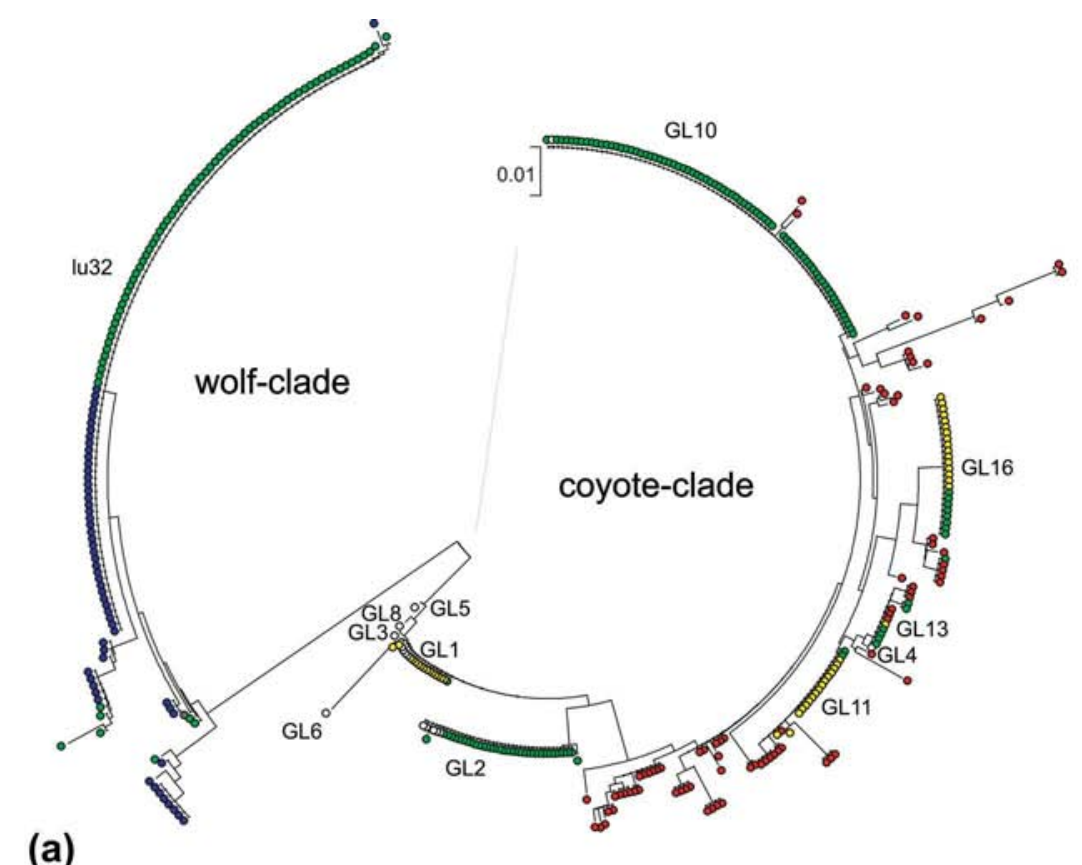

(a)

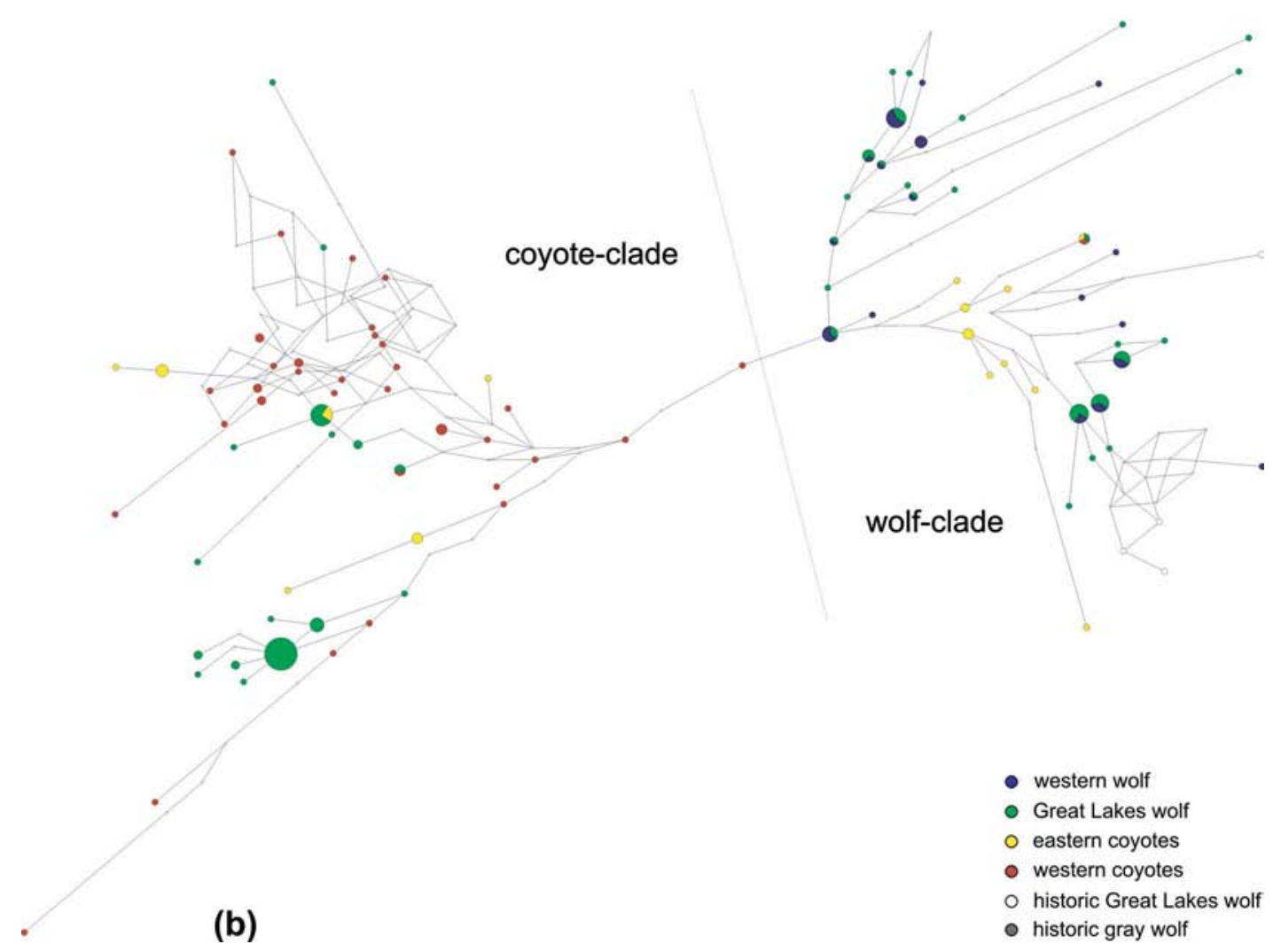

Fig. 2 (a) Neighbour-joining tree (HKY + I + G distances) of mitochondrial control region sequences sampled in modern western gray wolves, GL wolves, western and eastern coyotes and historic gray and GL wolves. Haplotype designations refer to GL haplotypes identified by Leonard \& Wayne (2008) and the most common wolf haplotype in North America (lu32; Leonard et al. 2005). Bootstrap support was only high for the split between the two major clades (bootstrap 100), whereas it was generally very low within the clades. (b) Median-joining network of Y-chromosomal haplotypes in modern western gray wolves, GL wolves, western and eastern coyotes, and historic GL wolves. The size of each circle is proportional to the haplotype frequency. Shared haplotypes are represented by circles with mixed colours, in which the relative frequency is indicated by the proportion of the different colours. Branch lengths are proportional to the number of nucleotide differences. Small open circles represent median vectors. 


\begin{tabular}{lllll}
\hline & Gray wolf & GL wolf & Coyote E & Coyote W \\
\hline Mitochondrial DNA & & & & \\
$N$ & 58 & 202 & 48 & 78 \\
$H$ & 8 & 19 & 7 & 46 \\
$H_{\mathrm{D}}$ & $0.575 \pm 0.071$ & $0.741 \pm 0.018$ & $0.780 \pm 0.030$ & $0.982 \pm 0.005$ \\
$\pi$ & $0.006 \pm 0.004$ & $0.045 \pm 0.022$ & $0.016 \pm 0.009$ & $0.018 \pm 0.009$ \\
Y-chromosome & & & & \\
$N$ & 30 & 111 & 25 & 41 \\
$H$ & 17 & 41 & 15 & 34 \\
$H_{\mathrm{D}}$ & $0.936 \pm 0.027$ & $0.896 \pm 0.034$ & $0.947 \pm 0.025$ & $0.990 \pm 0.008$ \\
\hline
\end{tabular}

Table 2 Mitochondrial and Y-chromosomal diversity of North American wolf like canids (excluding historic samples)

$N$, sample size; $H$, number of haplotypes; $H_{\mathrm{D}}$, haplotype diversity; $\pi$, nucleotide diversity.

wolf and coyote-clade haplotypes, respectively. Most of the historic GL wolves (haplotypes GL8, GL5, GL1, GL6, GL2) occupied the most basal branches in the coyote clade; only two possessed more derived haplotypes (haplotypes GL4, GL10). Due to low bootstrap support, except for the wolfcoyote split, no definite conclusions on the chronologic appearance of haplotypes can be drawn based on branching order. Three haplotypes found in the historic samples were also present in modern GL wolves (GL1, GL2, GL10). Of these, GL1 was also quite frequent in eastern coyotes. Other haplotypes shared between GL wolves and eastern coyotes are GL11, GL13 and GL16. Of these, GL11 and GL13 were also found in western coyotes. One haplotype (la28; Hailer \& Leonard 2008) was exclusively shared between GL wolves and western coyotes. Most GL wolves that were assigned to the wolf clade had haplotype lu32, the most common haplotype in American gray wolves (Leonard et al. 2005). Haplotype diversity in GL wolves was much higher than that in western gray wolves, and was highest in eastern and western coyotes (Table 2). The occurrence of both wolf- and coyote-clade haplotypes in GL wolves resulted in extraordinarily high nucleotide diversity compared to the other taxa (Table 2). Differentiation between historic and modern GL wolf haplotypes was significant with $\theta_{\mathrm{ST}}=0.2404$ and $P<0.0001$.

\section{Y-chromosomal data}

Y-chromosomal diversity was generally high, but lowest in GL wolves, and highest in western coyotes (Table 2). Similar to the mitochondrial sequence data, the medianjoining network based on Y-chromosomal haplotypes revealed a separation into a wolf and a coyote clade, with GL wolf haplotypes present in both clades (Fig. 2b). Unlike the mitochondrial data, eastern coyote haplotypes appeared in both clades. Only one western coyote haplotype from Illinois, the border zone between western and eastern coyotes, was found in the wolf clade, sharing its haplotype with both an eastern coyote and a GL wolf. Whereas nine haplotypes were shared between GL wolves and western wolves, only three haplotypes were shared between GL wolves and coyotes (two in the coyote clade, one in the wolf clade). As in the mitochondrial data, no clear geographical substructuring was evident within GL wolves. Each of the four historic GL wolves which were successfully genotyped at all six Y-chromosome loci had a unique haplotype in the wolf-clade. Within the coyote clade, two major GL wolf clusters were evident. The first cluster, which includes the most frequent as well as eight additional GL-specific haplotypes, is closely related to four divergent western coyotes. In the second cluster, the most frequent haplotype is shared between GL-wolves and eastern coyotes and is closely related to, but not nested within, the majority of the western coyotes.

\section{Autosomal microsatellites}

Microsatellite diversity was similar in the western gray wolves, GL wolves, eastern and western coyotes (Table 3), with slightly less diversity in wolves than in coyotes. Slight, but significant departure from Hardy-Weinberg expectations at, and linkage disequilibrium between, several loci indicate some degree of population substructure within and introgression into GL wolves. Extreme heterozygote deficiency at loci Ren239K24 and u225 in the eastern coyotes and Ren239K24 in the western coyotes might indicate the presence of null alleles; however, this should not have a large effect on the assignment tests performed (Carlsson 2008).

Structure analyses showed a peak in $\Delta K$ (Evanno et al. 2005) for $K=2$, corresponding to two clusters, which separated wolves (western gray wolf plus GL wolf) and coyotes (Fig. 3a-c). However, the log-likelihood values $[\ln \operatorname{Pr}(X \mid K)]$ consistently increased up to $K=4$, where the curve reached a plateau such that $\ln \operatorname{Pr}(X \mid K)$ for values of $K>4$ were almost identical (Fig. 3a). For $K=3$, the three clusters separated gray wolf, GL wolf and coyote, and for $K=4$, clusters corresponded to gray wolf, GL wolf, eastern and western coyotes (Fig 3c). Although $\Delta K$ for $K$ of 3 and 4 were lower than for $K=2$ (Fig. 3b), the distribution of samples into 


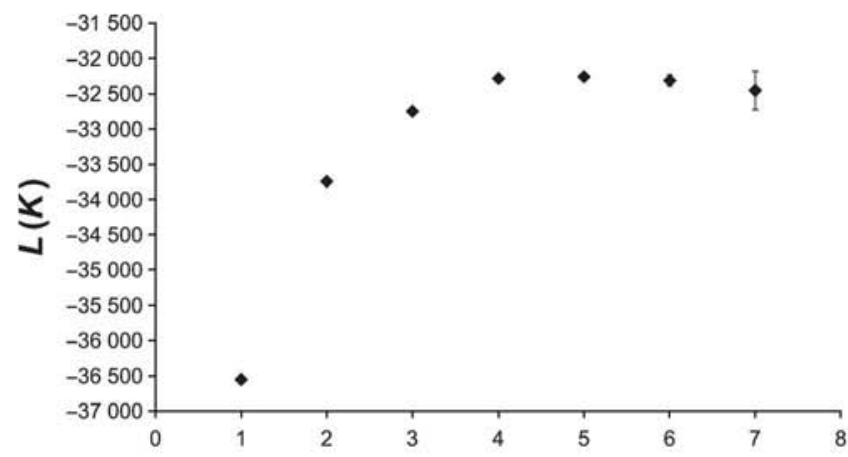

(a)

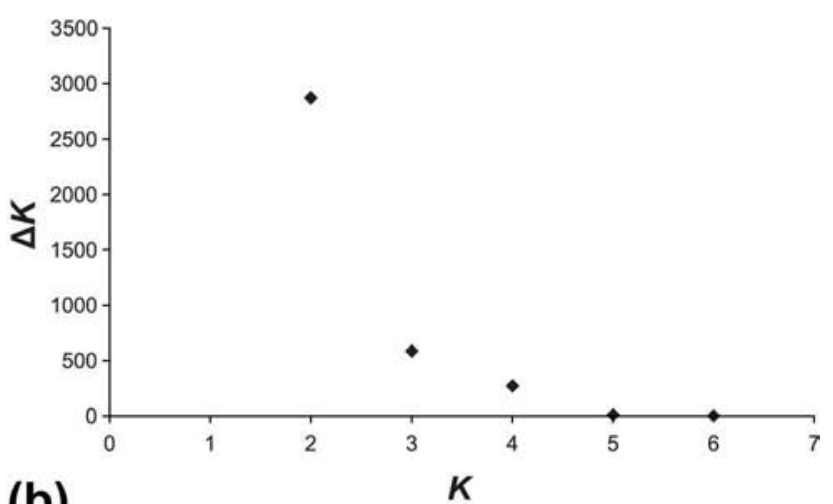

(b)
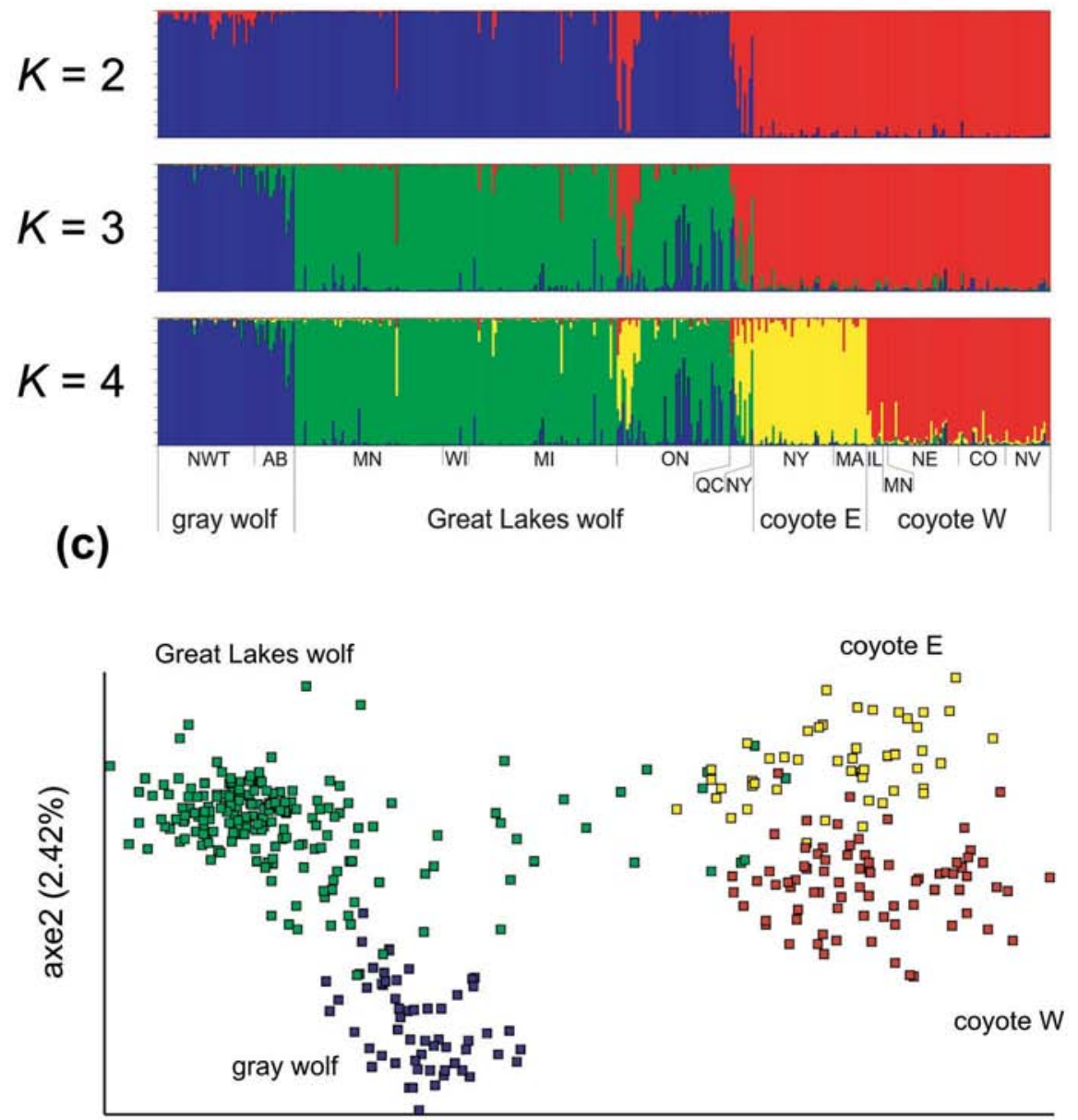

(d)

$\operatorname{axe} 1(5.23 \%)$

Fig. 3 Clustering analysis in recent North American wolf-like canids, using (a-c) Bayesian assignment and (d) a factorial correspondence analysis. (a) Mean likelihood $[L(K) \pm \mathrm{SD}$ ] over 10 runs assuming $K$ clusters $(K=1-7)$. (b) $\Delta K$, where the modal value of the distribution is considered as the highest level of structuring. (c) Individual assignment to each of the $K(K=2-4)$ clusters. Each individual is represented by a bar, with coloured sections indicating the likelihood of assignment to the corresponding cluster. NWT, Northwest Territories; AB, Alberta; MN, Minnesota; WI, Wisconsin; MI, Michigan; ON, Ontario; QC, Quebec; NY, New York; MA, Massachusetts; NE, Nebraska; CO, Colorado; NV, Nevada; IL, Illinois. (d) Results of the factorial correspondence analysis, showing the first two axes. Western gray wolves, GL wolves, eastern coyotes and western coyotes are depicted in blue, green, yellow and red, respectively. 
Table 3 Microsatellite diversity in North American wolf-like canids (excluding historic samples)

\begin{tabular}{|c|c|c|c|c|c|c|c|c|c|c|c|c|c|c|c|c|c|}
\hline \multirow[b]{2}{*}{ Locus } & \multicolumn{4}{|c|}{$\begin{array}{l}\text { Gray wolf } \\
(n=58)\end{array}$} & \multicolumn{4}{|c|}{$\begin{array}{l}\text { GL wolf } \\
(n=195)\end{array}$} & \multicolumn{4}{|c|}{$\begin{array}{l}\text { Coyote E } \\
(n=48)\end{array}$} & \multicolumn{4}{|c|}{$\begin{array}{l}\text { Coyote W } \\
(n=78)\end{array}$} & \multirow{2}{*}{$\begin{array}{l}\text { Historic GL } \\
\text { wolf }(n=13)^{*} \\
N_{\mathrm{A}}\end{array}$} \\
\hline & $N_{\mathrm{A}}$ & $A_{\mathrm{R}}$ & $H_{\mathrm{o}}$ & $H_{\mathrm{E}}$ & $N_{\mathrm{A}}$ & $A_{\mathrm{R}}$ & $H_{\mathrm{O}}$ & $H_{\mathrm{E}}$ & $N_{\mathrm{A}}$ & $A_{\mathrm{R}}$ & $H_{\mathrm{O}}$ & $H_{\mathrm{E}}$ & $N_{\mathrm{A}}$ & $A_{\mathrm{R}}$ & $H_{\mathrm{O}}$ & $H_{\mathrm{E}}$ & \\
\hline Ren94K11 & 8 & 7.8 & 0.655 & 0.785 & 10 & 8.2 & 0.728 & 0.731 & 8 & 8.0 & 0.750 & 0.713 & 11 & 9.6 & 0.846 & 0.837 & 8 \\
\hline C17.402 & 6 & 5.8 & 0.621 & 0.685 & 9 & 7.6 & 0.692 & 0.754 & 9 & 8.9 & 0.729 & 0.827 & 9 & 8.9 & 0.744 & 0.795 & 6 \\
\hline FH3109 & 7 & 6.8 & 0.793 & 0.816 & 9 & 5.9 & 0.631 & 0.703 & 7 & 7.0 & 0.870 & 0.812 & 11 & 10.8 & 0.833 & 0.860 & 4 \\
\hline Ren239K24 & 7 & 6.8 & 0.741 & 0.741 & 13 & 7.7 & 0.677 & 0.679 & 8 & 8.0 & 0.500 & 0.811 & 8 & 7.6 & 0.384 & 0.767 & - \\
\hline C18.460 & 8 & 7.6 & 0.672 & 0.779 & 9 & 7.1 & 0.656 & 0.675 & 10 & 10.0 & 0.851 & 0.793 & 11 & 9.6 & 0.769 & 0.845 & 6 \\
\hline Ren274F18 & 7 & 6.9 & 0.690 & 0.681 & 9 & 7.7 & 0.703 & 0.735 & 7 & 7.0 & 0.787 & 0.813 & 11 & 9.5 & 0.769 & 0.802 & 5 \\
\hline Ren181K04 & 8 & 7.8 & 0.603 & 0.700 & 9 & 7.8 & 0.610 & 0.731 & 9 & 9.0 & 0.604 & 0.788 & 11 & 10.4 & 0.833 & 0.878 & 6 \\
\hline FH2887 & 6 & 6.0 & 0.638 & 0.645 & 11 & 8.0 & 0.682 & 0.717 & 7 & 6.9 & 0.750 & 0.777 & 11 & 10.6 & 0.833 & 0.840 & 7 \\
\hline C11.873 & 7 & 7.0 & 0.741 & 0.781 & 9 & 8.2 & 0.749 & 0.828 & 7 & 7.0 & 0.896 & 0.814 & 12 & 11.1 & 0.833 & 0.866 & 8 \\
\hline FH2914 & 8 & 8.0 & 0.862 & 0.845 & 8 & 6.2 & 0.713 & 0.751 & 4 & 4.0 & 0.667 & 0.623 & 8 & 7.2 & 0.718 & 0.730 & 7 \\
\hline FH2785 & 9 & 9.0 & 0.810 & 0.842 & 12 & 9.3 & 0.626 & 0.634 & 11 & 10.8 & 0.750 & 0.720 & 16 & 14.6 & 0.846 & 0.888 & - \\
\hline Ren73F08 & 4 & 4.0 & 0.603 & 0.574 & 7 & 5.9 & 0.651 & 0.680 & 7 & 7.0 & 0.875 & 0.793 & 13 & 12.2 & 0.705 & 0.740 & 4 \\
\hline C02.894 & 9 & 9.0 & 0.724 & 0.795 & 10 & 8.9 & 0.749 & 0.825 & 10 & 10.0 & 0.854 & 0.844 & 10 & 9.2 & 0.821 & 0.813 & 8 \\
\hline Ren37H09 & 9 & 8.8 & 0.776 & 0.811 & 9 & 7.9 & 0.708 & 0.764 & 8 & 8.0 & 0.771 & 0.844 & 10 & 9.8 & 0.872 & 0.871 & 9 \\
\hline Ren204K13 & 5 & 4.8 & 0.569 & 0.674 & 7 & 6.3 & 0.718 & 0.730 & 6 & 6.0 & 0.833 & 0.732 & 8 & 7.4 & 0.769 & 0.778 & - \\
\hline Ren160J02 & 10 & 9.7 & 0.638 & 0.786 & 11 & 9.3 & 0.713 & 0.799 & 9 & 9.0 & 0.702 & 0.728 & 6 & 5.4 & 0.397 & 0.430 & - \\
\hline FH2759 & 8 & 8.0 & 0.828 & 0.823 & 11 & 8.6 & 0.810 & 0.826 & 10 & 10.0 & 0.851 & 0.845 & 12 & 11.4 & 0.769 & 0.805 & 5 \\
\hline Ren49F22 & 8 & 7.8 & 0.793 & 0.815 & 10 & 8.0 & 0.662 & 0.703 & 6 & 6.0 & 0.404 & 0.439 & 7 & 5.4 & 0.423 & 0.470 & 6 \\
\hline Ren106I06 & 8 & 8.0 & 0.793 & 0.822 & 12 & 11.5 & 0.795 & 0.845 & 7 & 7.0 & 0.804 & 0.832 & 12 & 11.3 & 0.795 & 0.884 & - \\
\hline u253 & 6 & 5.7 & 0.328 & 0.381 & 8 & 6.8 & 0.697 & 0.715 & 9 & 8.9 & 0.792 & 0.783 & 9 & 9.0 & 0.756 & 0.868 & 5 \\
\hline u2017 & 3 & 3.0 & 0.362 & 0.349 & 6 & 4.5 & 0.282 & 0.273 & 6 & 5.9 & 0.729 & 0.722 & 9 & 8.3 & 0.667 & 0.743 & - \\
\hline u109 & 7 & 6.8 & 0.879 & 0.762 & 7 & 6.1 & 0.579 & 0.591 & 7 & 7.0 & 0.688 & 0.766 & 10 & 9.6 & 0.795 & 0.837 & 5 \\
\hline u225 & 4 & 4.0 & 0.724 & 0.648 & 5 & 4.7 & 0.703 & 0.688 & 7 & 7.0 & 0.298 & 0.765 & 8 & 7.8 & 0.705 & 0726 & 5 \\
\hline u250 & 8 & 7.8 & 0.776 & 0.814 & 7 & 6.1 & 0.605 & 0.674 & 9 & 8.9 & 0.667 & 0.739 & 11 & 10.0 & 0.744 & 0.862 & 6 \\
\hline vWF & 7 & 6.8 & 0.724 & 0.761 & 9 & 6.8 & 0.631 & 0.688 & 8 & 8.0 & 0.792 & 0.838 & 9 & 8.6 & 0.756 & 0.834 & 6 \\
\hline PEZ05 & 4 & 4.0 & 0.603 & 0.639 & 7 & 6.1 & 0.682 & 0.661 & 6 & 6.0 & 0.750 & 0.780 & 6 & 6.0 & 0.756 & 0.774 & 3 \\
\hline Mean & 7.0 & 6.8 & 0.690 & 0.721 & 9.0 & 7.4 & 0.671 & 0.708 & 7.8 & 7.7 & 0.729 & 0.767 & 10.0 & 9.3 & 0.736 & 0.790 & 6.0 \\
\hline SD & 1.8 & 1.7 & 0.130 & 0.125 & 2.0 & 1.5 & 0.095 & 0.106 & 1.6 & 1.6 & 0.141 & 0.083 & 2.2 & 2.1 & 0.132 & 0.110 & 1.5 \\
\hline
\end{tabular}

$N_{\mathrm{A}}$, number of alleles per locus; $A_{\mathrm{R}}$, allelic richness; $H_{\mathrm{O}}$, observed heterozygosity; $H_{\mathrm{E}}$, expected heterozygosity. Deviations of $H_{\mathrm{O}}$ from HardyWeinberg expectations at a significance level of 0.05 after Benjamini-Hochberg (1995) correction are indicated by bold print. ${ }^{*}$ The six loci with the largest allele sizes were not used for the historic samples due to bad amplification results; heterozygosity estimates are not shown because of potential allelic dropout.

three and four clusters corresponded well to geographical groupings. We assume that the drop in $\Delta K$ reflects less substructure within wolves and within coyotes than between the two species. This conclusion is also suggested by the FCA analysis where axis 1 explained most of the variance and clearly differentiated wolves from coyotes (Fig. 3d). Axis 2 separated GL wolves from western gray wolves and eastern from western coyotes.

Both Structure and FCA analyses showed that GL wolves were distinct from western Canadian wolves, but the clear separation may in part be due to the lack of wolf samples from intervening areas. Supporting this conclusion is the presence of admixed genotypes in Alberta and further east in Ontario that show western wolf and GL wolf influences. In contrast, the most geographically disparate wolf populations in Northwest Territories and southeast in
Minnesota, Wisconsin and Michigan showed little evidence of admixture (Fig. 3c).

Despite the overall distinction between western gray wolves, GL wolves and coyotes, GL individuals with mixed ancestry were identified in Structure based on the autosomal microsatellite data. These individuals, that are likely $\mathrm{F}_{1}$ hybrids, have varied combinations of Y-chromosomal and mtDNA haplotypes, which indicates a prior history of hybridization. Surprisingly, some GL wolf individuals with high proportions of eastern coyote autosomal DNA had wolf-like Y-chromosomal and mtDNA haplotypes. Also, some GL wolf individuals with high proportions of western gray wolf autosomal DNA had coyote-clade Ychromosomal and mtDNA haplotypes. All these data point to recurrent incidents of hybridization in the ancestry of these individuals. 
Although we detect evidence for past episodic and ongoing hybridization between GL wolves, coyotes and western wolves, there is no indication of a unique hybrid origin of the GL wolf. If the GL wolves owed their origin to a discrete episode of past hybridization, we would expect them to have consistently mosaic genotypes in the structure analysis and an intermediate position between western wolves and coyotes in the FCA plot. Rather, our results are consistent with previous studies that showed varying degrees of ongoing and historic introgression across the Great Lakes area. For example, as in Lehman et al. (1991), our microsatellite results suggest introgression of coyote genetic material into GL wolves is much more prominent north of the Great Lakes (Ontario, Quebec) than in the south (Minnesota, Wisconsin, Michigan). Thus, the Great Lakes area appears to be a zone of limited hybridization between gray wolves, GL wolves and coyotes.

The test for heterozygosity excess revealed no evidence for a recent genetic bottleneck in the GL wolves $(P=0.945)$. Although it is known that GL wolves experienced a severe bottleneck in the last century, the allelic signal has apparently been eroded due to high levels of introgression from both coyotes and other wolf populations. Alternatively, the bottleneck may have been limited in geographical scope to the US Great Lakes states which were rapidly repopulated by wolves from Canada that have suffered less of a population decline.

Modern GL wolves differed significantly from the modern western gray wolves $\left(\theta_{\mathrm{ST}}=0.0775, P<0.0001\right)$, eastern $\left(\theta_{\mathrm{ST}}=0.1419, P<0.0001\right)$ and western coyotes $\left(\theta_{\mathrm{ST}}=0.1329\right.$, $P<0.0001$ ), indicating genetic isolation between GL wolves and both coyotes and western gray wolves. The average number of alleles scored per historic sample (at 20 loci) was 33 (SD 6.7, range 17-40). The average number of alleles used to calculate $\theta_{\text {ST }}$ per microsatellite locus was 20.5 (SD 2.6, range 16-26). Using the subset of 20 microsatellite loci which amplified most successfully from the historic material, the genetic composition of the historic GL wolves differed significantly from that of western gray wolves $\left(\theta_{\mathrm{ST}}=0.0572\right.$, $P<0.0001)$, eastern $\left(\theta_{\mathrm{ST}}=0.1225, P<0.0001\right)$ and western coyotes $\left(\theta_{\mathrm{ST}}=0.0898, P<0.0001\right)$. The majority of the 20 analysed loci were significantly differentiated between the historic GL wolves and the western gray wolves (13 loci), eastern (19 loci) and western coyotes (17 loci) (Appendix). In contrast, only five loci showed significant differentiation between the historic and modern GL wolves (Appendix), whereas the remaining 15 loci were not differentiated between the historic and modern samples, despite the observed highly significant mitochondrial differentiation (see above and Leonard \& Wayne 2008). Apparently, some degree of genetic continuity has been retained over the last century despite population bottlenecks and current hybridization with coyotes and other wolf populations. Nonetheless, despite the low number of significantly differentiated loci and the low global $\theta_{\text {ST }}$ value of 0.0355 , differentiation between the historic and the recent GL sample was significant with a global $P<0.0001$.

\section{Discussion}

\section{Evolutionary history of the Great Lakes wolf}

The autosomal microsatellite data clearly indicate that the GL wolves should be considered gray wolves, despite the high proportion of coyote-like mitochondrial and Ychromosomal haplotypes. The numerous GL wolf haplotypes (or haplotype groups) in the coyote clade in the mtDNA and Y-chromosomal data, in particular the ones present in the historic samples and not shared with western coyotes, point to recurrent incidents of ancient introgression from coyotes into the GL wolves. Since western coyotes apparently show no distinct phylogeographical substructuring (Lehman

\& Wayne 1991), this lack of haplotype sharing between historic GL wolves and western coyotes indicates that sufficient time has passed since introgression for new haplotypes to evolve, rather than being an artefact due to insufficient geographical sampling of coyotes. We do not find evidence for a unique grouping of GL wolves in microsatellite, mtDNA or Y-chromosome analyses that would support the past presence of a unique species of wolf in the Great Lakes area (Wilson et al. 2000; Kyle et al. 2006), nor do we find evidence for a unique episode of hybridization that might have led to the intermediate phenotype of wolves throughout the region (Nowak 2002).

The Great Lakes wolves constitute a small-sized wolf ecotype that is adapted to the intermediate prey base of the region (Schmitz \& Lavigne 1987). Abundant evidence for ecological based factors explaining phenotypic and genetic diversity of gray wolves in the New and Old World is accumulating (Carmichael et al. 2001, Geffen et al. 2004; Pilot et al. 2006; Musiani et al. 2007; Carmichael et al. 2007; Muñoz-Fuentes et al. 2009). For example, ecotypes associated with coastal habitats, Arctic islands, tundra, boreal forest and the Pleistocene megafauna have been identified (Musiani et al. 2007; Carmichael et al. 2007; Leonard et al. 2007; Muñoz-Fuentes et al. 2009). Many of these ecotypes have evolved recently, in the past 10000 years with the retreat of the Laurentide and Cordilleran ice sheets. The GL wolves, however, have likely had a long history, perhaps 300000 years, based on mtDNA sequence divergence (Leonard \& Wayne 2008). Therefore, the Great Lakes ecotype may have persisted for a long time period despite genetic exchange with coyotes and other gray wolves.

The presence of coyote clade haplotypes in historic GL wolves suggests an ancient history of interbreeding between coyotes and GL wolves. Hybridization between GL wolves and coyotes may be more likely when the former is relatively rare (Lehman et al. 1991). This condition may 
have occurred repeatedly with the recurrent cycles of glaciation and deglaciation in the Pleistocene and the associated change in range and the relative abundance of the two species in eastern North America. Our results are consistent with the idea that glacial cycles repeatedly pushed the GL wolves southward into the original range of coyotes where they experienced introgression from the resident species. However, the reason why hybridization between coyotes and wolves is so extensive in the Great Lakes area and not elsewhere in Canada or the USA where the species now co-exist is uncertain, but it may have to do with the smaller disparity in size between GL wolves and coyotes (e.g. Lehman et al. 1991; Roy et al. 1994; Pilgrim et al. 1998; Hailer \& Leonard 2008).

\section{Recent hybridization between wolf-like canids in the Great Lakes region}

In addition to evidence for ancient introgression of coyote mitochondrial and Y-chromosomal DNA into GL wolves, our results suggest extensive recent and ongoing hybridization between GL wolves and both coyotes and other populations of gray wolves. Microsatellite genotypes and mtDNA haplotypes suggested the presence of recently admixed wolves in the Great Lakes region (Fig. 3c, d). Similarly, significant mitochondrial differentiation between historic and modern GL wolves is consistent with extensive recent gene flow between GL wolves and eastern coyotes and other wolf populations. In contrast, little recent gene flow between GL wolves and eastern coyotes is indicated by Ychromosomal data, suggestive of sex-biased introgression (see Lehman et al. 1991).

The recent gene flow between GL wolves and eastern coyotes is surprising given that coyote abundance is usually limited by wolves in areas where they coexist by direct killing (e.g. Paquet 1992) and interference competition (Murray Berger \& Gese 2007). However, once coyotes are established in an area, their extirpation is unlikely as spatial heterogeneity in habitat and in wolf distribution facilitate the persistence of coyotes in wolf-abundant areas (Murray Berger \& Gese 2007). Coyotes are usually found in more urban and agricultural regions, whereas wolves occur in more remote pristine areas. These habitats are closely juxtaposed in the Great Lakes region and consequently, coyotes and GL wolves often live in close proximity, increasing the opportunity for interspecific interactions and matings.

The extent of hybridization varies throughout the Great Lakes area. Microsatellite data indicate that the wolves north of the Great Lakes are much more impacted by hybridization with coyotes and other gray wolf populations than areas to the south, a result supported by previous mtDNA analyses (Lehman et al. 1991). A clear cline in body size from large individuals in the northwest to small individuals in the southeast has been observed and hypothesized to result from varying degrees of hybridization between North American wolf-like canids (Kyle et al. 2006). However, the extent to which this morphological cline is due to differential hybridization or adaptation and environmental constraints (Schmitz \& Lavigne 1987) remains to be determined. A similar cline in body size has been observed in wolves from Minnesota, again interpreted as corresponding to different degrees of hybridization between GL wolves and western gray wolves (Mech \& Paul 2008), although contrary to the situation in Ontario, the Minnesota wolves appear less impacted by hybridization in our analysis (Fig. 2c).

\section{Population integrity and implications for conservation}

A substantial change in the frequency of maternally inherited mitochondrial DNA haplotypes between historic and recent GL wolves was previously described (Leonard \& Wayne 2008), and was further supported by the haplotype distributions and levels of mtDNA differentiation found in the present study. The dramatic change in haplotype composition reflects recent hybridization and introgression of both coyote and western gray wolf mtDNA into the GL wolf population (Leonard \& Wayne 2008) and hence a change in the genetic composition of that population (Leonard \& Wayne 2008, 2009). Autosomal microsatellite data detected comparatively slight — but significant - genetic differentiation between historic and modern GL wolves, but high levels of differentiation between GL wolves and western gray wolves, eastern and western coyotes. This suggests that, despite population bottlenecks in the early 1900s and gene flow from coyotes and western gray wolves, the GL population has retained genetic distinction from coyotes and wolves elsewhere. Gene flow that occurred after the bottleneck could have in part restored previous genotypic diversity. It is also possible that the demographic bottleneck in US GL wolves was not sufficient to create a signal of a bottleneck over the entire Great Lakes population. These two factors are not mutually exclusive and both may have contributed to the lack of signal for demographic change.

The exact level of introgression of coyote and/or western gray wolf nuclear genetic material is unknown. However, the discovery of admixed individuals in the microsatellite analysis, and the mixed profile of Y-chromosome and mtDNA haplotypes in GL wolves shows that recent introgression must have occurred. In addition to the data presented here, the results of Roy et al. (1994) which found lower microsatellite differentiation between wolves and coyotes in the Great Lakes area than elsewhere, also support recent hybridization. With evidence for ancient hybridization, introgression into GL wolves was apparently not only a human-mediated phenomenon. However, despite 
high levels of introgression from coyotes, autosomal markers support GL wolves as a discrete wolf taxon.

The habitat in the Great Lakes region has changed dramatically over the last century, especially due to the large-scale conversion of forests to agriculture. These habitat changes, in combination with direct persecution of the gray wolves, led to the decline of the wolf and enabled the natural colonization of the area by coyotes. The habitat continues to change, as many farms are abandoned and the forests are now expanding. Nonetheless, it is very unlikely that coyotes will cease to be a part of this ecosystem in the foreseeable future. Hybridization between the GL wolves and especially eastern coyotes appears to be ongoing, and thus still has the potential to further undermine the integrity of the GL wolves. The hybridization does not appear to impact all GL wolves equally, so more information on the variation in ecological factors and the extent of hybridization in the different regions could help determine which circumstances favour hybridization, and provide guidelines for management to maintain GL wolf integrity in the future.

\section{Acknowledgements}

For providing samples we would like to thank Tom Cooley (Michigan Department of Natural Resources), John Hart, Bill Paul, D. Pete Sahr, Shawn Mcdowell (USDA APHIS Wildlife Services, Minnesota), John Hobbs, Ronald Fryder, Wayne Homan, Randy Benben (USDA APHIS Wildlife Services, Nebraska), Roland Kays (New York State Museum), Thomas Decker (Vermont Department of Fish \& Wildlife), Craig Coolahan (USDA APHIS Wildlife Services, California), Bob Beach (USDA Wildlife Services, Nevada), George Hubert (Illinois Department of Natural Resources) and Bob Fisher (National Museum of Natural History, Smithsonian Institution). We are grateful to Kristina M. Sefc for valuable comments on the analyses and for providing scripts to handle large amounts of data; and to Carles Vilà for comments on the manuscript. Financial support was provided by the Carl Tryggers Foundation, the Sven and Lilly Lawski Foundation, the Swedish Research Council and the National Science Foundation (NSF; OPP 0352634 and OPP-IOS 0733033). Logistical support was provided by Jesus Maldonado and the Center for Conservation and Evolutionary Genetics, National Zoological Park, Smithsonian Institution, USA.

\section{References}

Arnold MJ (1997) Natural Hybridization and Evolution. Oxford University Press, Oxford, UK.

Arnold MJ (1992) Natural hybridization as an evolutionary process. Annual Review of Ecology and Systematics, 23, 237-261.

Abbott RJ (1992) Plant invasions, interspecific hybridization and the evolution of new plant taxa. Trends in Ecology \& Evolution, 7, 401-405.

Bandelt HJ, Forster P, Sykes BC, Richards MB (1995) Mitochondrial portraits of human populations using median networks. Genetics, 141, 743-753.

Bandelt HJ, Forster P, Rohl A (1999) Median-joining networks for inferring intraspecific phylogenies. Molecular Biology and Evolution, 16, 37-48.
Bannasch DL, Dannasch MJ, Ryun JR, Famula TR, Pedersen NC (2005) Y chromosome haplotype analysis in purebred dogs. Mammalian Genome, 16, 273-280.

Belkhir K, Borsa P, Chikhi L, Raufaste N, Bonhomme F (19962004) Genetix 4.05, logiciel sous Windows TM pour la génétique des populations. Laboratoire Génome, Populations, Interactions, CNRS UMR 5171, Université de Montpellier II, Montpellier, France.

Benjamini Y, Hochberg Y. (1995) Controlling the false discovery rate: a practical and powerful approach for multiple testing. Journal of the Royal Statistical Society. Series B, 57, 289-300.

Berthier P, Excoffier L, Ruedi M (2006) Recurrent replacement of mtDNA and cryptic hybridization between two sibling bat specie Myotis myotis and Myotis blythii. Proceedings of the Royal Society B: Biological Sciences, 273, 3101-3109.

Björnerfeldt S, Hailer F, Nord M, Vilà C (2008) Assortative mating and fragmentation within dog breeds. BMC Evolutionary Biology, 8, 28.

Breen M, Jouquand S, Renier C et al. (2001) Chromosome-specific single-locus FISH probes allow anchorage of an 1800-marker integrated radiation-hybrid/linkage map of the domestic dog genome to all chromosomes. Genome Research, 11, 1784-1795.

Carlsson J (2008) Effects of microsatellite null alleles on assignment testing. Journal of Heredity, 99, 616-623.

Carmichael LE, Nagy JA, Larter NC, Strobeck C (2001) Prey specialization may influence patterns of gene flow in wolves of the Canadian northwest. Molecular Ecology, 10, 2787-2798.

Carmichael LE, Krizan J, Nagy JA et al. (2007) Historical and ecological determinants of genetic structure in arctic canids. Molecular Ecology, 16, 3466-3483.

Cornuet JM, Luikart G (1996) Description and power analysis of two tests for detecting recent population bottlenecks from allele frequency data. Genetics, 144, 2001-2014.

Currat M, Ruedi M, Petit RJ, Excoffier L (2008) The hidden side of invasions: massive introgression by local genes. Evolution, 62, 1908-.

Dowling TE, Secor C (1997) The role of hybridization and introgression in the diversification of animals. Annual Review of Ecology and Systematics, 28, 593-619.

Ellstrand NC, Schierenbeck KA (2000) Hybridization as a stimulus for the evolution of invasiveness in plants? Proceedings of the National Academy of Sciences, USA, 97, 7043-7050.

Evanno G, Regnaut S, Goudet J (2005) Detecting the number of clusters of individuals using the software Structure: a simulation study. Molecular Ecology, 8, 2611-2620.

Excoffier L, Laval G, Schneider S (2005) Arlequin (version 3.0): an integrated software package for population genetics data analysis. Evolutionary Bioinformatics Online, 1, 47-50.

Falush D, Stephans M, Pritchard JK (2007) Inference of population structure using multilocus genotype data: dominant markers and null alleles. Molecular Ecology Notes, 7, 574-578.

Francisco LV, Langston AA, Mellersh CS, Neal CL, Ostrander EA (1996) A class of highly polymorphic tetranucleotide repeats for canine genetic mapping. Mammalian Genome, 7, 359-362.

Geffen E, Anderson MJ, Wayne RK (2004) Climate and habitat barriers to dispersal in the highly mobile grey wolf. Molecular Ecology, 13, 2481-2490.

Guyon R, Lorentzen TD, Hitte C et al. (2003) A 1-Mb resolution radiation hybrid map of the canine genome. Proceedings of the National Academy of Sciences, USA, 100, 5296-5301.

Hailer F, Leonard JA (2008) Hybridization among three native North American Canis species in a region of natural sympatry. PLoS one, 3, e3333. 
Hasegawa M, Kishino H, Yano T (1985) Dating of the human-ape splitting by a molecular clock of mitochondrial DNA. Journal of Molecular Evolution, 22, 160-174.

Jouquand S, Priat C, Hitte C et al. (2000) Identification and characterization of a set of 100 tri- and dinucleotide microsatellites in the canine genome. Animal Genetics, 31, 266-272.

Keane TM, Creevey CJ, Pentony MM, Naughton TJ, McInerney JO (2006) Assessment of methods for amino acid matrix selection and their use on empirical data shows ad hoc assumptions of matrix are not justified. BMC Evolutionary Biology, 6, 29.

Kyle CJ, Johnson AR, Patterson BR et al. (2006) Genetic nature of eastern wolves: past, present and future. Conservation Genetics, 7, 273-287.

Lehman N, Wayne RK (1991) Analysis of coyote mitochondrialDNA genotype frequencies - estimation of the effective number of alleles. Genetics, 128, 405-416.

Lehman N, Eisenhawer A, Hansen K et al. (1991) Introgression of coyote mitochondrial DNA into sympatric North American gray wolf populations. Evolution, 45, 104-119.

Leonard JA, Vilà C, Wayne RK (2005) Legacy lost: genetic variability and population size of extirpated US gray wolves (Canis lupus). Molecular Ecology, 14, 9-17.

Leonard JA, Vilà C, Fox-Dobbs K, Koch PL, Wayne RK, Van Valkenburgh B (2007) Megafaunal extinctions and the disappearance of a specialized wolf morph. Current Biology, 17, 11461150 .

Leonard JA, Wayne RK (2008) Native GL wolves were not restored. Biology Letters, 4, 95-98.

Leonard JA, Wayne RK (2009) Wishful thinking: imagining that the current Great Lakes wolf is the same entity that existed historically. Biology Letters, 5, 67-68.

Luikart G, Sherwin WB, Steele BM, Allendorf FW (1998) Usefulness of molecular markers for detecting population bottlenecks and monitoring genetic change. Molecular Ecology, 7, 963-974.

Mech LD, Paul WJ (2008) Wolf body mass cline across Minnesota related to taxonomy? Canadian Journal of Zoology, 86, 933-936.

Melo-Ferreira J, Boursot P, Suchentrunk F, Ferrand N, Alves PC (2005) Invasion from the cold past: extensive introgression of mountain hare (Lepus timidus) mitochondrial DNA into three other hare species in northern Iberia. Molecular Ecology, 14, 2459-2464.

Muñoz-Fuentes V, Darimont CT, Wayne RK, Paquet P, Leonard JA (2009) Ecological factors drive differentiation in wolves from British Columbia. Journal of Biogeography, [Epub ahead of print] doi: 10.1111/j.1365-2699.2008.02067.x.

Murray Berger K, Gese EM (2007) Does interference competition with wolves limit the distribution and abundance of coyotes? Journal of Animal Ecology, 76, 1075-1085.

Musiani M, Leonard JA, Cluff HD et al. (2007) Differentiation of tundra/taiga boreal coniferous forest wolves: genetics, coat color and association with migratory caribou. Molecular Ecology, 16, 4149-4170.

Nowak RM (2002) The original status of wolves in eastern North America. Southeastern Naturalist, 1, 95-130.

O’Brien SJ, Mayr E (1991) Bureaucratic mischief: recognizing endangered species and subspecies. Science, 251, 1198-1199.

Ostrander EA, Sprague GF, Rine J (1993) Identification and characterization of dinucleotide repeat (CA) $n$ markers for genetic-mapping in dog. Genomics, 16, 207-213.

Paquet PC (1992) Prey use strategies of sympatric wolves and coyotes in Riding Mountain National Park, Manitoba. Journal of Mammalogy, 73, 337-343.
Patterson N, Richter DJ, Gnerre S, Lander ES, Reich D (2006) Genetic evidence for complex speciation of humans and chimpanzees. Nature, 441, 1103-1108.

Pilgrim KL, Boyd DK, Forbes SH (1998) Testing for wolf-coyote hybridization in the Rocky Mountains using mitochondrial DNA. Journal of Wildlife Management, 62, 683-689.

Pilot M, Jedrzejewski W, Branicki W et al. (2006) Ecological factors influence population genetic structure of European grey wolves. Molecular Ecology, 15, 4533-4553.

Piry S, Luikart G, Cornuet J-M (1999) Bottleneck: a computer program for detecting recent reductions in the effective population size using allele frequency data. Journal of Heredity, 90, 502-503.

Polzin T, Daneschmand SV (2003) On Steiner trees and minimum spanning trees in hypergraphs. Operations Research Letters, 31, $12-20$.

Roca AL, Georgiadis N, O’Brien SJ (2005) Cytonuclear genomic dissociation in African elephant species. Nature Genetics, 37, 96-100.

Roy MS, Geffen E, Smith D, Ostrander E, Wayne RK (1994) Patterns of differentiation and hybridization in North American wolf-like canids revealed by analysis of microsatellite loci. Molecular Biology and Evolution, 11, 553-570.

Sambrook J, Fritsch EF, Maniatis T (1989) Molecular Cloning: A Laboratory Manual. Cold Spring Harbor Laboratory Press, Cold Spring Harbor, New York.

Schmitz OJ, Lavigne GB (1987) Factors affecting body size in sympatric Canis. Journal of Mammalogy, 68, 92-99.

Seehausen O (2004) Hybridization and adaptive radiation. Trends in Ecology \& Evolution, 19, 198-207.

Sefc KM, Payne RB, Sorenson MD (2003) Microsatellite amplification from museum feather samples: effects of fragment size and template concentration on genotyping errors. Auk, 120, 982-989.

Shibuya H, Collins BK, Huang TH, Johnson GS (1994) A polymorphic (AGGAAT)n tandem repeat in an intron of canine von Willebrand factor gene. Animal Genetics, 25, 122.

Stouffer SA, Suchman EA, DeVinney LC, Star SA, Williams RA Jr (1949) The American Soldier, Vol. 1: Adjustment during Army Life. Princeton University Press, Princeton, New Jersey.

Sundqvist A-K, Ellegren H, Olivier M, Vilà C (2001) Y chromosome haplotyping in Scandinavian wolves (Canis lupus) based on microsatellite markers. Molecular Ecology, 10, 1959-1966.

Swofford DL (2002) PAuP*. Phylogenetic Analysis Using Parsimony ( ${ }^{*}$ and Other Mehods), Version 4.0. Sinauer \& Associates, Sunderland, Massachusetts.

Taberlet P, Griffin S, Goossens B et al. (1996) Reliable genotyping of samples with very low DNA quantities using PCR. Nucleic Acids Research, 15, 3189-3195.

Tamura K, Dudley J, Nei M, Kumar S (2007) mega 4: molecular evolutionary genetics analysis (mega) software version 4.0. Molecular Biology and Evolution, 24, 1596-1599.

van Oosterhout C, Hutchinson WF, Wills DP, Shipley P (2004) Micro-Checker: software for identifying and correcting genotyping errors in microsatellite data. Molecular Ecology Notes, 4, 535-538.

Vilà C, Amorim IR, Leonard JA et al. (1999) Mitochondrial DNA phylogeography and population history of the gray wolf Canis lupus. Molecular Ecology, 8, 2089-2103.

Weir BS, Cockerham CC (1984) Estimating F-statistics for the analysis of population structure. Evolution, 38, 1258-1370.

Whitlock MC (2005) Combining probability from independent tests: the weighted $Z$-method is superior to Fisher 's approach. Journal of Evolutionary Biology, 18, 1368-1373. 
Wilson PJ, Grewal S, Lawford ID etal. (2000) DNA profiles of eastern Canadian wolf and red wolf provide evidence for a common evolutionary history independent of the gray wolf. Canadian Journal of Zoology, 78, 2156-2166.

Maria Nord worked on the wolves as part of a fellowship project, and this project reflects her general interest in conservation biology. Since then she has begun her PhD on bird diversity in the Swedish archipelago and the effects of human disturbance. Stephan Koblmüller and Robert Wayne apply molecular genetic techniques to study questions in ecology, behaviour, conservation and evolution of animals. Jennifer Leonard combines genetic and other data to determine how and why populations are structured through time and space, and which factors drive some populations to extinction or expansion.
Note added in proof: Additional genetic analysis of the Great Lakes wolf was recently published by Wheeldon \& White (2009) which further supports the conclusions presented here.

Wheeldon T, White BN (2009) Genetic analysis of historic western Great Lakes region wolf samples reveals early Canis lupus/lycaon hybridization. Biology Letters, 5, 101-104. 


\section{Appendix}

Locus-by-locus $\theta_{\mathrm{ST}}$ and corresponding $P$ values (in parentheses) between historic Great Lakes (GL) wolves and modern GL wolves, western gray wolves, eastern and western coyotes. Significant $P$ values (at the $5 \%$ level) are indicated in bold lettering.

\begin{tabular}{|c|c|c|c|c|c|c|c|c|c|c|}
\hline & \multicolumn{10}{|l|}{ Locus } \\
\hline & Ren94K11 & C17.402 & FH3109 & C18.460 & Ren274F18 & Ren181K04 & FH2887 & C11.873 & FH2914 & Ren73F08 \\
\hline Modern GL wolf & $\begin{array}{c}0.0806 \\
\mathbf{( 0 . 0 0 2 7 )}\end{array}$ & $\begin{array}{c}0.0159 \\
(0.1446)\end{array}$ & $\begin{array}{c}0.0600 \\
\mathbf{( 0 . 0 2 1 2 )}\end{array}$ & $\begin{array}{c}0.0289 \\
(0.0546)\end{array}$ & $\begin{array}{c}0.0272 \\
(0.1171)\end{array}$ & $\begin{array}{c}0.0158 \\
(0.1678)\end{array}$ & $\begin{array}{c}-0.0130 \\
(0.6309)\end{array}$ & $\begin{array}{c}0.1448 \\
(<\mathbf{0 . 0 0 0 1 )}\end{array}$ & $\begin{array}{c}0.0223 \\
(0.1173)\end{array}$ & $\begin{array}{c}-0.0092 \\
(0.6168)\end{array}$ \\
\hline Gray wolf & $\begin{array}{c}0.0666 \\
(\mathbf{0 . 0 0 5 2})\end{array}$ & $\begin{array}{c}0.0010 \\
(0.3582)\end{array}$ & $\begin{array}{c}0.0217 \\
(0.1172)\end{array}$ & $\begin{array}{c}0.00435 \\
(\mathbf{0 . 0 2 0 0 )}\end{array}$ & $\begin{array}{c}0.0999 \\
(\mathbf{0 . 0 0 7 3})\end{array}$ & $\begin{array}{c}0.0035 \\
(0.3210)\end{array}$ & $\begin{array}{c}-0.0066 \\
(0.4390)\end{array}$ & $\begin{array}{c}0.1479 \\
(<\mathbf{0 . 0 0 0 1 )}\end{array}$ & $\begin{array}{c}0.0813 \\
\mathbf{( 0 . 0 0 0 8 )}\end{array}$ & $\begin{array}{l}-0.0156 \\
(0.6833)\end{array}$ \\
\hline Coyote E & $\begin{array}{c}0.1522 \\
(<\mathbf{0 . 0 0 0 1 )}\end{array}$ & $\begin{array}{c}0.0314 \\
(0.0508)\end{array}$ & $\begin{array}{c}0.0799 \\
\mathbf{( 0 . 0 0 3 6 )}\end{array}$ & $\begin{array}{c}0.0735 \\
\mathbf{( 0 . 0 0 1 1 )}\end{array}$ & $\begin{array}{c}0.0740 \\
\mathbf{( 0 . 0 0 9 9 )}\end{array}$ & $\begin{array}{c}0.2151 \\
(<\mathbf{0 . 0 0 0 1})\end{array}$ & $\begin{array}{c}0.1626 \\
\mathbf{( 0 . 0 0 0 1 )}\end{array}$ & $\begin{array}{c}0.1181 \\
(<\mathbf{0 . 0 0 0 1 )}\end{array}$ & $\begin{array}{c}0.2018 \\
\mathbf{( 0 . 0 0 0 1 )}\end{array}$ & $\begin{array}{c}0.0589 \\
\mathbf{( 0 . 0 1 1 3 )}\end{array}$ \\
\hline \multirow[t]{3}{*}{ Coyote W } & $\begin{array}{c}0.0540 \\
\mathbf{( 0 . 0 0 5 2 )}\end{array}$ & $\begin{array}{c}0.0758 \\
\mathbf{( 0 . 0 0 1 0 )}\end{array}$ & $\begin{array}{c}0.0441 \\
\mathbf{( 0 . 0 1 3 8 )}\end{array}$ & $\begin{array}{c}0.0377 \\
\mathbf{( 0 . 0 1 5 0 )}\end{array}$ & $\begin{array}{c}0.1316 \\
\mathbf{( 0 . 0 0 0 2 )}\end{array}$ & $\begin{array}{c}0.1767 \\
\mathbf{(}<\mathbf{0 . 0 0 0 1 )}\end{array}$ & $\begin{array}{c}0.0820 \\
\mathbf{( 0 . 0 0 2 0 )}\end{array}$ & $\begin{array}{c}0.0900 \\
\mathbf{(}<\mathbf{0 . 0 0 0 1 )}\end{array}$ & $\begin{array}{c}0.1523 \\
(<\mathbf{0 . 0 0 0 1 )}\end{array}$ & $\begin{array}{c}0.0294 \\
\mathbf{( 0 . 0 5 3 0 )}\end{array}$ \\
\hline & \multicolumn{10}{|l|}{ Locus } \\
\hline & C02.894 & Ren37H09 & FH2759 & Ren49F22 & u253 & u109 & u225 & u250 & vWF & PEZ05 \\
\hline Modern GL wolf & $\begin{array}{c}0.0580 \\
\mathbf{( 0 . 0 0 2 9 )}\end{array}$ & $\begin{array}{c}0.0164 \\
(0.1740)\end{array}$ & $\begin{array}{c}0.0091 \\
(0.2160)\end{array}$ & $\begin{array}{c}0.0125 \\
(0.1936)\end{array}$ & $\begin{array}{c}0.0108 \\
(0.2131)\end{array}$ & $\begin{array}{c}-0.0041 \\
(0.4604)\end{array}$ & $\begin{array}{c}0.0141 \\
(0.1760)\end{array}$ & $\begin{array}{c}0.1179 \\
\mathbf{( 0 . 0 0 0 5 )}\end{array}$ & $\begin{array}{c}0.0102 \\
(0.2209)\end{array}$ & $\begin{array}{c}0.0334 \\
(0.1007)\end{array}$ \\
\hline Gray wolf & $\begin{array}{c}0.0074 \\
(0.2434)\end{array}$ & $\begin{array}{c}0.0726 \\
\mathbf{( 0 . 0 0 7 5 )}\end{array}$ & $\begin{array}{c}0.0456 \\
(\mathbf{0 . 0 2 2 5})\end{array}$ & $\begin{array}{c}0.0728 \\
\mathbf{( 0 . 0 0 2 6 )}\end{array}$ & $\begin{array}{c}0.0705 \\
\mathbf{( 0 . 0 2 1 5 )}\end{array}$ & $\begin{array}{c}0.1636 \\
\mathbf{(}<\mathbf{0 . 0 0 0 1 )}\end{array}$ & $\begin{array}{c}0.0511 \\
\mathbf{( 0 . 0 3 7 9 )}\end{array}$ & $\begin{array}{c}0.0540 \\
\mathbf{( 0 . 0 0 5 8 )}\end{array}$ & $\begin{array}{c}0.0901 \\
\mathbf{( 0 . 0 0 1 6 )}\end{array}$ & $\begin{array}{r}-0.0090 \\
0.5155\end{array}$ \\
\hline Coyote E & $\begin{array}{c}0.0805 \\
\mathbf{( 0 . 0 0 0 2 )}\end{array}$ & $\begin{array}{c}0.0432 \\
\mathbf{( 0 . 0 2 5 3 )}\end{array}$ & $\begin{array}{c}0.1197 \\
\mathbf{( 0 . 0 0 0 1 )}\end{array}$ & $\begin{array}{c}0.2650 \\
(<\mathbf{0 . 0 0 0 1 )}\end{array}$ & $\begin{array}{r}0.1877 \\
(<\mathbf{0 . 0 0 0 1 )}\end{array}$ & $\begin{array}{c}0.1422 \\
\mathbf{( 0 . 0 0 0 2 )}\end{array}$ & $\begin{array}{c}0.0461 \\
\mathbf{( 0 . 0 2 8 9 )}\end{array}$ & $\begin{array}{c}0.1714 \\
(<\mathbf{0 . 0 0 0 1 )}\end{array}$ & $\begin{array}{c}0.0894 \\
\mathbf{( 0 . 0 0 0 5 )}\end{array}$ & $\begin{array}{c}0.1493 \\
(<\mathbf{0 . 0 0 0 1 )}\end{array}$ \\
\hline Coyote W & $\begin{array}{c}0.0842 \\
(\mathbf{0 . 0 0 0 8 )}\end{array}$ & $\begin{array}{c}0.0223 \\
(0.0808)\end{array}$ & $\begin{array}{c}0.0716 \\
(\mathbf{0 . 0 0 3 7 )}\end{array}$ & $\begin{array}{c}0.2777 \\
(<\mathbf{0 . 0 0 0 1 )}\end{array}$ & $\begin{array}{c}0.0663 \\
\mathbf{( 0 . 0 0 1 6 )}\end{array}$ & $\begin{array}{r}0.1369 \\
(<\mathbf{0 . 0 0 0 1})\end{array}$ & $\begin{array}{c}0.0203 \\
(0.1121)\end{array}$ & $\begin{array}{c}0.0283 \\
\mathbf{( 0 . 0 3 1 8 )}\end{array}$ & $\begin{array}{c}0.0967 \\
(\mathbf{0 . 0 0 0 3 )}\end{array}$ & $\begin{array}{c}0.1215 \\
\mathbf{( 0 . 0 0 0 2 )}\end{array}$ \\
\hline
\end{tabular}

